\title{
Ley № 20.084 sobre Responsabilidad Penal de Adolescentes
}

\author{
Miguel Cillero Bruñol*
}

\section{Antecedentes Generales}

Tras un largo proceso de deliberación legislativa, se aprobó la Ley № 20.084 (D.O. 7.12.2005), modificatoria del Código Penal (CP) y la Ley de Menores, cuerpo legal que "establece un sistema de responsabilidad de los adolescentes por infracciones a la ley penal". Esta reforma representa una sustancial transformación del sistema jurídico chileno en lo que se refiere al estatuto personal de la aplicación de la ley penal en razón de la edad.

La regulación legal de esta materia había sido objeto de profundas críticas por la doctrina nacional y observaciones formales del Comité de Derechos del Niño de Naciones Unidas, que denunciaban el desajuste entre la legislación de menores vigente y las obligaciones adquiridas por Chile al momento de ratificar instrumentos internacionales de Derechos Humanos. Esta situación afectaba gravemente los derechos de los niños y adolescentes imputados por infracciones a la ley penal, quienes estaban sometidos al modelo del discernimiento, un modelo condicional de imputabilidad, caracterizado por la discrecionalidad judicial para apreciar la concurrencia de los elementos subjetivos relativos a la capacidad de culpabilidad.

El Presidente Ricardo Lagos, en el Mensaje del Proyecto de Ley (68-347 de 2 de agosto de 2002), plantea, en su primer párrafo, que este Proyecto se inscribe en el marco más amplio de la adecuación de la leyes y políticas de la infancia y adolescencia a los nuevos "requerimientos jurídicos y sociales (...) y a los principios y directrices contenidos en la Constitución Política de la República, la Convención Internacional sobre los Derechos del Niño y demás instrumentos internacionales vigentes en Chile".

El diagnóstico de la legislación nacional que hace el Presidente es indicativo de la gravedad del problema de vulneración de derechos que se pretende resolver con esta ley. "Desde un punto de vista jurídico, esta reforma se fundamenta en que la actual legislación de menores, en no pocas materias, entra en contradicción con disposiciones de la Constitución y de la Convención Internacional sobre los Derechos del Niño y, en algunos casos, directamente vulnera estos cuerpos jurídicos". Como ejemplos de esta anómala situación, el Mensaje cita "procesos sin forma de juicio; aplicación de medidas sin participación de abogados defensores y dictadas por tiempo indeterminado; sanciones privativas de libertad que vulneran el principio de legalidad a través de la utilización de fórmulas abiertas como la irregularidad, los desajustes conductuales o el peligro material o moral".

Este comentario, junto con el documento principal a que se refiere, están disponibles en www.anuariocdh.uchile.cl 
1 Véase Cillero, M. y Bernales, $M$. "Derechos Humanos de la Infancia/ Adolescencia en la justicia "penal de menores" de Chile: evaluación y perspectivas", en Revista Derechos del Niño, No. 1, UDP/ UNICEF, Santiago, 2002. El comentario al Anteproyecto 1998 en Alvear Valenzuela, S., "Comentario al Proceso de Reforma Legislativa en Chile". Sobre el Proyecto 2002 véase Cillero, $M$. y Maldonado, F., "El Proceso de Reforma Legislativa en Chile", publicados respectivamente en García, Méndez y Beloff, comp. Infancia, Ley y Democracia en América Latina, $1^{\mathrm{a}}$ ed. Temis/Depalma, Santa Fe de Bogotá, 1998 pp. 353 - 383 y en la $3^{3}$. Ed. ampliada de este libro, editorial Temis, Santa Fe de Bogotá, 2004, Tomo I. pp. $271-281$.

2 Véase al respecto la declaración pública del organismo de Naciones Unidas encargado del seguimiento de la Convención, UNICEF, en www.unicef.cl publicada también en Revista Electrónica General de Derecho Penal (España, Noviembre 2005, www.iustel.com).
El Mensaje identifica el núcleo del problema cuando señala que "se da la inconsecuencia que el sistema especial de menores, nacido para proteger los derechos de los niños, ha terminado por desmedrar su posición jurídica, situación que se ha hecho aún más evidente a partir del perfeccionamiento de la justicia penal de adultos con la entrada en vigencia del nuevo sistema de enjuiciamiento penal".

La pretensión de fortalecer la posición jurídica de los adolescentes ha de ser, entonces, uno de los parámetros a los que deben someterse la evaluación de las disposiciones del texto legal y los resultados de su aplicación práctica.

Junto al propósito de corregir esta situación, el Mensaje del Presidente enunciaba también otro problema: "Por su parte, desde un punto de vista social, es evidente que la preocupación pública por la seguridad ciudadana y el perfeccionamiento de la Justicia penal en todos los ámbitos ha crecido. La actual justicia de menores es objeto de críticas no sólo porque no se somete a los límites y controles que la Constitución establece para la jurisdicción criminal general, sino también, porque no satisface las exigencias de protección de los derechos de las víctimas de la delincuencia".

En los párrafos transcritos queda de manifiesto el marco jurídico y político criminal que el Gobierno tuvo en consideración al impulsar este Proyecto de Ley. Con él se pretendía plasmar un sistema complejo, que limitara las necesidades de prevención del delito con el reconocimiento de las garantías penales sustantivas y procesales, junto con asegurar la protección de los Derechos Humanos de la Infancia y la Adolescencia. Este diseño venía siendo elaborado trabajosamente desde 1994, aunque la necesidad de la reforma ya había sido puesta de manifiesto, en documentos oficiales del Ministerio de Justicia, incluso inmediatamente después del restablecimiento de la democracia ${ }^{1}$.

Sin embargo, al comparar la ley aprobada con el proyecto enviado por el Presidente, se constata que las modificaciones introducidas durante la tramitación parlamentaria fueron inspiradas, principalmente, por argumentos relativos a necesidades de prevención del delito y atendiendo al convencimiento de algunos legisladores de que el rigor punitivo y la mayor simetría entre el Derecho penal de adultos y el de adolescentes, tendrían como resultado la disminución de la delincuencia juvenil.

En consecuencia, los cambios experimentados afectaron principalmente a la intensidad de las sanciones y a sus mecanismos de determinación. Estas reformas materializaron un importante incremento de la punibilidad, lo que impide realizar una valoración positiva global de la ley desde la perspectiva de los Derechos Humanos de los niños y adolescentes ${ }^{2}$, pese a que en diversos aspectos se produce un notable avance en relación a la legislación vigente antes de la reforma.

En este comentario centraremos el interés en examinar los aspectos medulares de la ley en relación a los principios y derechos fundamentales 
limitadores del Derecho Penal y a las normas específicas del Derecho Internacional de los Derechos Humanos de protección de las personas menores de dieciocho años.

\section{Análisis de las disposiciones particulares de la ley}

a) Establecimiento de una franja de responsabilidad especial entre $14 \mathrm{y}$ 18 años (artículo 3 Ley $N^{\circ} 20.084$ )

Seguramente la innovación más importante contenida en la ley es la modificación del Código Penal que extiende la exención de responsabilidad penal de adultos para todas las personas menores de 18 años, poniendo término al sistema de responsabilidad penal condicionada al discernimiento entre los 16 y los 18 años.

La ley, al fijar el límite superior mediante un criterio cronológico, otorga una mayor seguridad jurídica y, en consecuencia, garantiza una mayor igualdad de todos los adolescentes. Con ello, al excluir a todas las personas menores de 18 años del régimen penal de adultos cumple con las exigencias contenidas en la Convención sobre los Derechos del Niño (CDN) y demás tratados internacionales sobre la materia.

Igualmente relevante resulta el establecimiento legal -en 14 años- del límite inferior de responsabilidad penal especial; esta disposición que viene a dar cumplimiento a lo dispuesto en el artículo 40.3. de la CDN. Este límite constituye una genuina y positiva novedad en el sistema jurídico nacional, pues impide, al menos en el plano normativo, la extensión del sistema punitivo formal por debajo de los catorce años. Sin embargo, preocupa que la propia IHey abra la posibilidad de aplicar, en sede de Tribunales de Familia, medidas de protección que, de no limitarse adecuadamente, podrían devenir en la aplicación de sanciones penales informales para las personas menores de 14 años a los que la ley califica como niños.

\section{b) Conductas típicas}

Otro de los importantes avances de esta ley es que se adecua a las exigencias del principio de legalidad de los delitos, remitiéndose a los tipos penales contenidos en la ley penal. Así se deroga la facultad judicial de aplicar medidas de contenido penal por la concurrencia de presupuestos abiertos como la irregularidad social o desajustes conductuales, que estaban establecidas en la legislación anterior. De esta forma, se equiparan las garantías de los adolescentes a las establecidas para los adultos.

Sin embargo, el objetivo de la creación de un sistema penal de adolescentes excede a la equiparación con el sistema penal de adultos en el ámbito de las conductas punibles. Por el contrario, la idea rectora del sistema debería ser reducir al máximo la intervención penal, para lo cual se hace necesario examinar si efectivamente es legítimo, desde un punto de vista valorativo, y conveniente, desde una perspectiva preventiva, 
3 Albrecht, P.A. "Respecto al futuro del derecho penal de menores", en Bustos, Juan, Director, Un Derecho Penal del Menor, Editorial Jurídica Conosur, Santiago, 1992. mantener una identidad o total simetría de los tipos penales de adultos y adolescentes.

Durante el largo período de estudio del Proyecto se hicieron propuestas y se redactaron anteproyectos que reducían el arco de conductas típicas punibles para los adolescentes. Esto es, se pretendió realizar un proceso de descriminalización primaria, de modo que el Derecho Penal de adolescentes sólo comprendiera conductas tipificadas para los adultos, pero no todas ellas ${ }^{3}$.

Particularmente relevante resultaba dejar fuera de este sistema de reacción penal a las faltas, criterio que el legislador siguió parcialmente, manteniendo algunas de estas en el sistema de responsabilidad penal de adolescentes, mientras que la sanción de las restantes quedó entregada a los Juzgados de Familia.

Asimismo, la existencia de un catálogo taxativo de delitos a los que se les podían aplicar sanciones privativas de libertad tenía como orientación político-criminal impedir la aplicación de sanciones privativas de libertad para delitos de gravedad mediana y leve.

\section{c) Consecuencias jurídicas}

La ley establece un conjunto de consecuencias jurídicas, que denomina preferentemente sanciones, aunque también utiliza indistintamente y de manera confusa las palabras penas y medidas (i.e. artículo 20). El impreciso uso de la terminología es un indicio de las imperfecciones de la ley al momento de caracterizar, delimitar y definir las consecuencias jurídicas, problema que adquiere gravedad en las disposiciones relativas a la determinación de las mismas (párrafo $V$, artículos 20 al 26). La redacción de este párrafo es oscura y el consecuente proceso de interpretación se torna bastante complicado e imprevisible, con lo que no se cumple adecuadamente con los criterios de seguridad jurídica que deben inspirar la legislación penal.

La clasificación principal de las consecuencias jurídicas contenida en la ley es la distinción entre sanciones privativas y no privativas de libertad. En el Proyecto del Ejecutivo, la distinción tenía sentido, pues se reservaban las sanciones privativas de libertad únicamente para las infracciones graves, taxativamente identificadas en el texto. Con esa redacción se pretendía cumplir con el principio constitucional de legalidad y con el mandato del artículo 37 b) de la CDN, que establece que la privación de libertad debe ser un último recurso y por el menor tiempo posible.

El Senado, en cambio, optó por una solución distinta que adolece de graves problemas, porque intenta asimilar los fines preventivos especiales positivos, que se dice inspiran la reforma, con los parámetros retributivos e intimidatorios propios del Código Penal chileno. A grandes rasgos, el sistema aprobado consiste en vincular la sanción aplicable a los adolescentes con la pena establecida en el Código Penal y, por medio de un sistema de conversión, determinar el marco penal aplicable a los 
adolescentes, dentro del cual el Juez procederá a individualizar la sanción concreta a imponer.

Los problemas formales de la fórmula aprobada tienen que ver, entre otros, con la marcada imprecisión de los términos jurídicos y la existencia de diversas normas contrapuestas, o alternativas, que regulan idéntica materia. Un caso preocupante es el de la determinación de la extensión de la pena en los artículos del citado título. Esta deficiente técnica legislativa se puede explicar porque las modificaciones introducidas en el Senado se agregaron al sistema de determinación propuesto por el Ejecutivo, duplicándose algunas reglas y haciendo perder sentido a otras.

Otro problema fundamental es la aplicación automática de idénticos criterios de agravación de las sanciones para adultos y adolescentes, materia que podría haber sido resuelta de un modo más cuidadoso que acogiera las distinciones que la criminología describe entre las conductas delictivas de adultos y adolescentes. Un ejemplo característico de este desconocimiento es que se establezca como agravante, y por ello se le valore como de mayor gravedad, la concurrencia de pluralidad de hechores, circunstancia que desde el punto de vista de los análisis de la criminalidad de adolescente no tiene sentido caracterizarla legalmente como indicativa de mayor gravedad ${ }^{4}$.

Asimismo, dada la confusión de las normas relativas a la determinación de la pena, y la deficiente construcción de las escalas penales, se puede afectar seriamente el principio de proporcionalidad y se puede Ilegar a valorar doblemente alguna de las circunstancias agravantes, en las sucesivas etapas que la ley establece para la determinación de la sanción.

Para la determinación la norma clave es la rebaja en un grado del mínimo de la pena contemplada para los adultos (artículo 21), a partir de la cual se hace la conversión a la sanción aplicable a los adolescentes. Esta rebaja es pareja para todos los delitos.

Como el Proyecto, adicionalmente a la rebaja, pone un tope máximo a la duración de la privación de libertad, se produce el problema que el sistema aprobado favorece proporcionalmente más a las penas que sobrepasen el máximo fijado para adolescentes que a aquellas que quedan dentro de los rangos inferiores. Esto se produce porque hay delitos que, pese a la rebaja en un grado del mínimo, quedarían sobre la extensión máxima y por ello se benefician de una segunda rebaja. Esta situación Ileva a que se rompa la proporcionalidad interna en el sistema penal de adolescentes, ya que las penas más altas no se reservan para los delitos más graves.

La razón que explica este problema es que el legislador equivocadamente vincula dos escalas de pena de duraciones diferentes, la de adultos con un máximo de 40 años y la de adolescentes con 10 años, a través de un mecanismo no proporcional, como es la rebaja en un grado del mínimo. En cambio, los sistemas decimonónicos de discernimiento proporcionalmente construidos, convertían la pena de adultos a través de un divisor común, por ejemplo, la rebaja a un tercio de la pena de
4 Véase Rutter, $M$, Giller, $\mathrm{H}$ y Hagell, A., La Conducta Antisocial de los Jóvenes, Cambridge University Press, Madrid, 2000, particularmente los estudios relativos a la influencia de los grupos coetáneos y a la actividad delictiva en grupos, pp. 270 278 . 
adultos, con lo cual mantenían la relación de proporcionalidad entre gravedad de los delitos e intensidad de las penas.

Actualmente, las legislaciones técnicamente más avanzadas elaboran, como lo hacía el Proyecto del Ejecutivo, una escala de sanciones independiente de la de los adultos, que recoge las valoraciones específicas adecuadas a las necesidades preventivas de la criminalidad adolescente, resguarda el principio de proporcionalidad y establece topes máximos que respetan el principio de brevedad de las sanciones privativas de libertad consagrado en la CDN.

Respecto a la duración de la pena, el problema no es solamente de construcción, sino también de fondo. Si se analiza el punto desde la perspectiva de los instrumentos internacionales, y de los propios principios contenidos en la ley, como los de interés superior del adolescente, privación de libertad como último recurso y primacía del carácter educativo de las sanciones, se verá que la decisión de elevar de cinco a diez años la duración máxima de la internación aplicable a los mayores de 16 años es inconsistente.

La virtud de una ley penal juvenil es resolver armónicamente las contradicciones entre libertad, seguridad y protección al desarrollo e integración social de los adolescentes. Para ello es necesaria la consistencia entre los fines de la intervención que se proclaman y los medios -las sanciones-que se disponen para el cumplimiento de dichos fines. En este sentido, resulta impropio que una sanción privativa de libertad-que puede llegar hasta los 10 años- se pretenda fundamentar en los supuestos efectos resocializadores.

Si el legislador, contrariando disposiciones expresas de los tratados internacionales, fija penas de esa magnitud, debería haber expresado directamente la prioridad de los fines disuasivos, retributivos y de control de las sanciones establecidas, sin pretender revestir su decisión de finalidades educativas o "responsabilizadoras" que, en la práctica, no son compatibles con la extensión y forma de determinación de sanciones que establece la ley.

Asimismo, el hecho que de los cinco tramos en que se ordenan las sanciones según el artículo 23 de la ley, cuatro de ellos contemplen la aplicación de sanciones privativas de libertad y que en el primero de ellos sólo se establezca este tipo de sanciones, revela que el principio, contenido en instrumentos internacionales y recogido explícitamente en la ley, de que la privación de libertad debe ser un último recurso, ha sido sobrepasado.

En consecuencia, producto de la deficiente técnica legislativa en materia de determinación de sanciones, se presentan serios problemas que afectan la seguridad jurídica, la proporcionalidad, la brevedad y el carácter de último recurso de las sanciones penales de adolescentes. 


\section{d) Derecho al Debido Proceso y Sistema de Justicia Especializado}

En este aspecto la ley en comento es un verdadero avance al establecer un sistema de juzgamiento que respeta las garantías procesales de los adolescentes, dando cumplimiento a las exigencias generales del debido proceso.

Sin embargo, analizada la normativa desde la perspectiva del Derecho Internacional de los Derechos Humanos, en particular de la Convención Americana sobre Derechos Humanos y de la CDN, se puede observar que el desarrollo de un sistema especializado es relativamente débil tanto en el aspecto orgánico como en los procedimientos.

Desde el punto de vista orgánico, se plantean dudas respecto a la suficiencia de las exigencias legales sobre especialización de los operadores del sistema de justicia, que quedan condicionadas a la distribución de la carga de trabajo (artículo 29). No obstante, esta insuficiencia puede ser mitigada mediante directivas del Poder Judicial, el Ministerio Público y la Defensoría Penal Pública.

En el ámbito procesal, la ley se mantiene demasiado apegada a las normas generales de enjuiciamiento propias de los adultos, pudiendo haber optado, en cambio, por la creación de un sistema que, otorgando iguales garantías, estuviera dotado de mayor autonomía y especificidad ${ }^{5}$.

\section{Conclusión}

En atención a lo expuesto, la Ley de Responsabilidad Penal de Adolescentes constituye una reforma necesaria, cuya mayor virtud es derogar el sistema de discernimiento y los procesos judiciales informales vigentes actualmente, dotándolos de las garantías elementales.

Sin embargo, la ley no logra consolidar un sistema de reemplazo adecuado a la normativa internacional sobre derechos humanos. Por el contrario, su rigor punitivo, su defectuoso sistema de determinación de sanciones y la debilidad de su especialidad, tanto sustantiva como procesal y en la fase de ejecución de las sanciones, hacen temer que ella pueda ser fuente de nuevas vulneraciones de derechos.

Ciertamente estos defectos pueden ser mitigados con el esfuerzo de los diferentes operadores del sistema, y esperamos que así ocurra, pero los problemas de fondo que la ley presenta sólo podrán ser corregidos a través de cambios legislativos.
5 Al respecto, véase Corte IDH, Opinión Consultiva OC-17/02, Condición Jurídica y Derechos Humanos del Niño, de 28 de agosto de 2002, Serie A № 17. 
